\title{
Analysis of Influencing Factors of Civil-Military Integration Equipment Maintenance Support Mode Based on ISM
}

\author{
Situ Chengyuan \\ Department of Basic Courses \\ Ordnance Engineering College, OEC \\ Shijiazhuang, China \\ situchengyuan@sina.com
}

\author{
Huang Shaoluo \\ Department of Basic Courses \\ Ordnance Engineering College, OEC \\ Shijiazhuang, China
}

\begin{abstract}
This study summarizes 8 influencing factors of civil-military integration equipment maintenance support mode. To clarify the relationship between them, using the ISM method we transformed the two relation matrix into a matrix which reflects the logical relation according to causality. After reduction, we obtained the graph with a clear structure. The result shows that the private enterprise and the combat mission are the two most important factors. When deciding which model to adopt, we should focus on these two factors.
\end{abstract}

Keywords - civil-military integration; Equipment maintenance support mode; influence factors; ISM

\section{INTRODUCTION}

Civil-military integration equipment maintenance support mode refers to the relatively stable organization form and practice procedures in order to complete the equipment maintenance support under the guidance of the theory of civilmilitary integration. At present, theoretical research results of civil-military integration equipment maintenance support are abundant, but the research involving the model is less, and the pertinence and guidance are not strong. On the basis of analyzing the existing models, it is a prerequisite and basis for building a new model to establish a more perfect system of influencing factors.

\section{PRESENT SITUATION}

Now, countries pay more and more attention to the maintenance of equipment maintenance, and according to their own national conditions, equipment development, technical level and ability to gradually explore the formation of appropriate equipment maintenance model. If we want to successfully complete equipment maintenance tasks in wartime, we should aim at wartime protection as soon as possible, strengthen the importance, perfect the efficient guarantee system and operation mode [1].Under the market economy condition, the operation mode of military civilian integration equipment maintenance support is mainly based on contract. At present, there are 8 types of contractors' safeguards in the major national armies: outsource, joint, leased, supported, locally privatized, delegated, requisition, and employment [2].As showed in Table 1.

TABLE I. THE CONTRACTUAL PROTECTION MODEL OF MAJOR NATIONAL ARMIES

\begin{tabular}{|l|l|c|}
\hline \multicolumn{1}{|c|}{ Mode name } & \multicolumn{1}{|c|}{ Operation mode } & National armies \\
\hline Outsource & $\begin{array}{l}\text { To subcontract parts of the military } \\
\text { system or equipment to local professional } \\
\text { maintenance units or original equipment } \\
\text { manufacturers }\end{array}$ & U.S.A \\
\hline Joint & $\begin{array}{l}\text { Joint local security forces to form a } \\
\text { cooperative team }\end{array}$ & U.S.A \\
\hline Leased & $\begin{array}{l}\text { Local companies rent the facilities of the } \\
\text { military base or the opposite }\end{array}$ & U.S.A \\
\hline Supported & $\begin{array}{l}\text { Local companies provide maintenance } \\
\text { technology to the military }\end{array}$ & U.S.A, Britain \\
\hline $\begin{array}{l}\text { Locally } \\
\text { privatized }\end{array}$ & $\begin{array}{l}\text { The government or the military transfers } \\
\text { the facility to the private enterprise }\end{array}$ & Finland \\
\hline Delegated & $\begin{array}{l}\text { Local enterprises represent the army for } \\
\text { maintenance }\end{array}$ & $\begin{array}{c}\text { Japan, } \\
\text { Germany }\end{array}$ \\
\hline Requisition & $\begin{array}{l}\text { Direct collection of local personnel, } \\
\text { facilities and equipment in accordance } \\
\text { with the law }\end{array}$ & All countries \\
\hline Employment & $\begin{array}{l}\text { Military paid employment and facilities } \\
\text { faritain }\end{array}$ & U.S.A, Britan \\
\hline
\end{tabular}

The above 8 modes of contract guarantee are based on the different ways of cooperation between the army and the local authorities. An application to the specific reality, a kind of equipment, military and civilian integration can be a variety of military cooperation by way of combination. According to the application of scientific and comprehensive principle, identified 8 factors: Maintenance support difficulty, Military civilian universal, secret degree, combat mission, military maintenance support force, research contractor, private enterprise, equipment maintenance support mechanism. The following factors for each type of specific analysis. 


\section{ANALYSIS OF INFLUENCING FACTORS}

\section{A. Maintenance support difficulty}

With the increase of technical concentration and complexity of equipment, the difficulty of equipment maintenance support is also increasing, and the army maintenance support force cannot complete the task of maintenance support alone. The "PBL" proposed and implemented by the US military will integrate the protection and acquisition from the purchase of spare parts, tools, technical information and training equipment into the purchase performance. Combat readiness integrity, economic and many other indicators of the duties was implemented to the contractor, the military only considers the acceptance of indicators [3]. Through the adoption of this strategy, equipment availability and combat readiness have been effectively improved. Implementation of the "PBL" project for the military to repair more difficult to support the equipment, such as F / A-18E-F Hornet, AH-64 attack helicopters.

\section{B. Military civilian versatility}

With the development of modern science and technology, Military technology and civil technology are converging, The scope of military and civilian general equipment is expanding day by day, and the types of military and civilian equipment are increasing, Such as transport vehicles, ships, aircraft, general machinery, communications satellites, reconnaissance and detection equipment, electronic computers, surveying and mapping equipment, meteorological equipment, engineering equipment, medical equipment and so on [4]. The military civilian versatility of the equipment component determines the degree of participation of the private enterprises to a large extent. The higher the general level of military and civilian equipment, the greater the possibility of private enterprises to participate in the maintenance support, and the role of market mechanism in optimizing the allocation of resources can be more fully used. For example, wheeled vehicles have strong military and civilian use, and can be secured by local military maintenance sites nearby.

\section{Secret degree}

Because of its military specificity, weapons and equipment are directly related to operations, and special components involving military secrets must be maintained by the army itself. When the part of the degree of confidentiality in general but the military itself does not have the ability to repair and support, if it belongs to the core business, should be made by the units to help the army to establish the maintenance of the service capacity, If it does not belong to the core business, in outsourcing to the research and development units or small and medium enterprises, should pay attention to the maintenance of security personnel and the implementation of the provisions of the confidentiality of the provisions.

\section{Combat mission}

With the accelerated pace of modern warfare, Accompanying safeguards will become the main mode of equipment restoration in the future battlefield. If the use of contractor security forces, the risk of maintenance is high, need some troops to protect. Usually contractors should be included in the equipment mobilization force. In wartime, according to operational tasks and wartime protection requirements, the military sole guarantee, the Contractor's individual protection and common security tasks are clearly defined. The two sides will work together on the basis of their respective responsibilities so as to ensure the successful completion of the task [5].

\section{E. Military maintenance support force}

The army maintenance support force is the foundation of equipment maintenance support force system, and is the main force in wartime rush repair. The overall construction level of the army maintenance support force is directly related to the completion of the wartime maintenance support task, and strengthening this part of the force is an important principle for the reform of the maintenance support mode. Although a large number of base maintenance support missions are outsourced to the contractors, the US military has attached great importance to the construction of the army base level maintenance support capability. The provisions of the tenth and 2464th sections of the code of the United States provide that the contractor shall not pay more than $50 \%$ of the total amount of the maintenance. In addition, the US military has quantified the core maintenance capabilities of the military as a specific maintenance effort, and determined its calculations in the DOD directive and conducted periodic reviews.

\section{F. Research contractor}

The research contractor has the advantage of maintenance support. The technical level of staff is higher. They are familiar with the performance and principle of equipment. In the development and production, we should plan the construction of maintenance support resources and transform the potential for maintenance support into strength. The army through the contract will be part of the non-core maintenance support task for the research contractors, while saving money can also improve the efficiency and efficiency of maintenance. The American Lockheed Martin, Boeing and other military giants and the army long-term cooperation, and formed a good relationship.

\section{G. Private enterprise}

The private enterprise here refers to other non-state-owned enterprises other than equipment manufacturers. The private enterprise usually participates in the equipment maintenance support in the form of scientific research and production. In particular, the accession of small and medium enterprises is conducive to the equipment maintenance work to further market, the formation of both the size of the competitive landscape. The United States government strongly supports technological innovation of small and medium-sized enterprises, and the U. S. Army produces special funds every year to collect the necessary products.

\section{H. Maintenance support mechanism}

Scientific, effective and flexible mechanism is the integration of military and civilian equipment maintenance guarantees the smooth conduct of the guarantee. The U.S. 
Army has established four levels of organization and management system for the Ministry of national defense and the League of nations, the armed services, the theater of operations and the joint combat forces, with a clear and reasonable division of labor at all levels. In addition to relying on the existing US regulatory agencies to carry out contract management to protect the management, but also set up a variety of committees on the contractor to protect the guidance, supervision and coordination. In order to guarantee the guarantee of wartime contractors, the US military, according to the general principle of guarantee of wartime contractors, stipulated the implementation mode of various military operations and various stages of warfare, and standardized the procedures and battlefield management mechanism of contract personnel.

\section{ANALYSIS OF INFLUENCING FACTORS BASED ON ISM}

Interpretative structural modeling(ISM) can decompose complex systems into a multi-level hierarchical structure, and can clarify the complex relationships between multiple elements to find key influencing factors.

The procedures and methods for establishing ISM models are mainly included [6]: A. Establish adjacency matrix. On the basis of a comprehensive and rational analysis of the influencing factors, the ISM group composed of experts, scholars and application personnel in this field, establish the adjacency matrix of the relationship between two factors. B. The adjacency matrix, which reflects the relationship between the two factors, is converted into a reachable matrix that reflects all relationships by a power operation based on Boolean algebraic operations. Consider the possible strong connection between the elements (mutual influence), only retain the representative elements, and form a matrix. C. Reduce the hierarchical processing of the matrix. D. Draw a multi - step ladder directed graph and establish an explanatory structural model.

\section{A. Establish adjacency matrix}

The adjacency matrix reflects the direct structural relationship between the different factors. Set adjacency matrix as $A=\left(a_{i j}\right)_{n \times n}$, Its elements are defined as

$$
a_{i j}=\left\{\begin{array}{l}
1, \text { when } a_{i} \text { has an impact on } a_{\mathrm{j}} \\
0, \text { when } a_{i} \text { has no impact on } a_{\mathrm{j}}
\end{array}, \mathrm{i}, \mathrm{j}=1,2, \cdots, \mathrm{n}\right.
$$

The foregoing analysis shows that, the factors influencing the civil-military integration mode include: Maintenance support difficulty, Military civilian universal, secret degree, combat mission, military maintenance support force, research contractor, private enterprise, equipment maintenance support mechanism, correspond to $a_{1} \sim a_{8}$. Through the ISM team's assessment, The adjacency matrix can be obtained

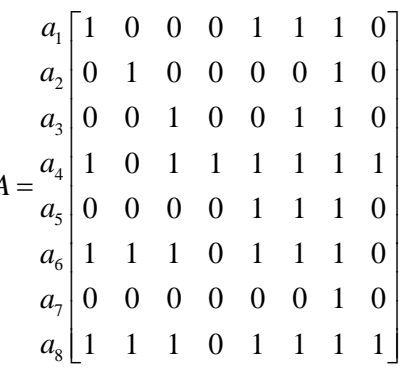

\section{B. Establish reachability matrix and reduced matrix}

Adjacency matrix can only reflect the direct relationship between the various factors, can not reflect the indirect relationship. The reachable matrix represents the path from one element to another, assume that any unit is reachable to itself, if matrix A satisfies the condition

$$
(A+I)^{k-1} \neq(A+I)^{k}=(A+I)^{k+1}=\mathrm{M}
$$

We call $\mathrm{M}$ as the reachable matrix of $\mathrm{A}$, where $\mathrm{I}$ is the unit matrix. Using Matlab software, we find out the reachable matrix of $\mathrm{A}$ as follows:

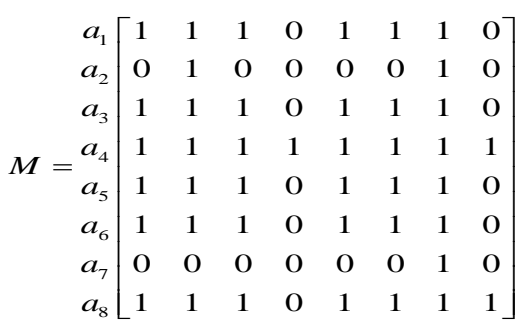

As the row and column $a_{1}, a_{3}, a_{5}, a_{6}$ are the same, the representative elements $a_{1}$ are retained, and the reduction matrix after deletion is

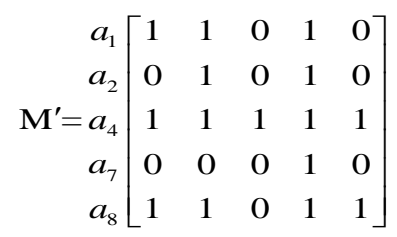

\section{Level processing}

In the reduced matrix $M^{\prime}$, the number of 1 in the row $a_{1}$ is 3 , the number of 1 in the row $a_{2}$ is 2 , the number of 1 in the row $a_{4}$ is 5 , the number of 1 in the row $a_{7}$ is 1 , and the number of 1 in the row $a_{8}$ is 4 . In accordance with the number of 1 per row, from less to more, and rearrange the matrix, the hierarchical processing of the matrix for

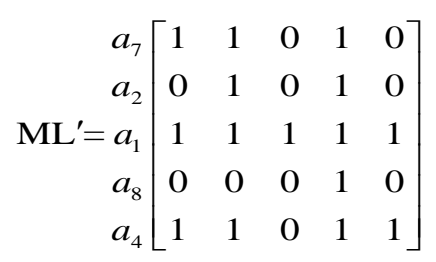




\section{Establish the model}

From the top left to the lower right of the matrix, the largest unit matrix is found, and the set of factors at different levels is gradually formed. Thus, a multistage step directed graph of the factors affecting the maintenance of the civil military fusion maintenance can be drawn, as showed in Figure 1.

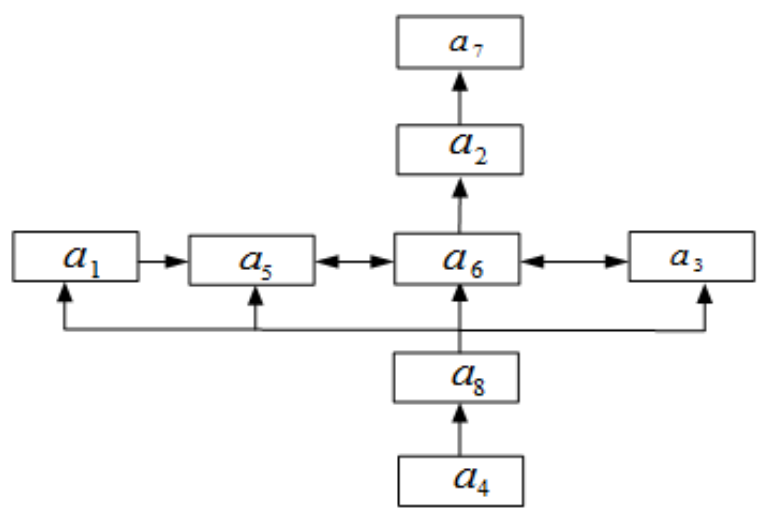

Fig. 1 Multistage ladder directed

From the model, it can be concluded that the private enterprise is the most direct factor. After the end of the Cold War, the US military in a timely manner a large number of military advanced technology to the civilian areas of transformation, so that a large number of private enterprises have the ability to participate in equipment maintenance. Today, a total of about more than a thousand companies and enterprises involved in the US military flat war maintenance tasks, in addition to Boeing as the representative of the larger original manufacturers, there are many smaller companies, accounting for contractors Guarantee the share of $35 \%$.
Equipment combat mission is the most fundamental factor. To build the model of military and civilian integration and maintenance, we should establish the equipment maintenance and repair system that conforms to the operational application, and further optimize the flow and material flow, information flow and improve the efficiency of maintenance.

\section{CONCLUSION}

This paper explores the relationship between the influencing factors based on the binary relationship. By using the ISM system analysis method, this paper constructs a structural model. It analyzes the direct factor and basic factor.

\section{REFERENCES}

[1] Hu Guangshen and Zhangjianying, "A study on optimization of equipment maintenance and support mode," RADRA AND ECM,2012.9 (In Chinese)

[2] Cai Liying and Liyuqiu, "Research on Every Contractor Support Mode and Revelations," Journal of Military Transportation University, 2012.5 (In Chinese)

[3] Liu Jiani,Wang linzhen,Liu Wei and Sun Jianbing, "Inspiration on American Army 'Performance-based Logistics' to Equipment Mobilization of Our Country," Journal of the Academy of Equipment Command \&Technology,2011.12 (In Chinese)

[4] Yu Gaoda and Zhao Lusheng ,"Military equipment science," National Defense University press,2000 (In Chinese)

[5] Hao Bing,Gao Lili and Li Zheng, "Analysis on the Feasibility and Risk Countermeasure of Wartime Contract Guarantee," National Defense Industry Press,2015 (In Chinese)

[6] Guo Yongheng,Gong Chuanxin,Li Wensheng, "Analysis of target ammunition demand factors based on ISM," Sichuan ordnance journal,2010(4)(In Chinese) 